\title{
Effects of Incorporation of Marine Derived Hydroxyapatite on the Microhardness and Surface Roughness of Two Glass-ionomer Cements ${ }^{+}$
}

\author{
Maja Bilić-Prcić ${ }^{1, *}$, Uzay Koç Vural ${ }^{2}$, Sevil Gurgan ${ }^{2}$, Ana Ivanišević ${ }^{1}$, Silvana Jukić Krmek ${ }^{1}$ and \\ Ivana Miletić ${ }^{1}$ \\ School of Dental Medicine, University of Zagreb, Gundulićeva 5, 10000 Zagreb, Croatia; \\ aivanisevic@sfzg.hr (A.I.); jukic@sfzg.hr (S.J.K.); miletic@sfzg.hr (I.M.) \\ School of Dentistry, Hacettepe University, Ankara 06100, Turkey; uzaykoc@gmail.com (U.K.V.); \\ sgurgan@gmail.com (S.G.) \\ * Correspondence: bilicprcic.maja@gmail.com \\ + Presented at the 1st International Electronic Conference on Applied Sciences, 10-30 November 2020; \\ Available online: https://asec2020.sciforum.net/. \\ Published: 10 November 2020

\begin{abstract}
Background: The aim of this study was to evaluate the effects of incorporation of hydroxyapatite (HA) derived from cuttlefish bone on the microhardness (MH) and surface roughness (SR) of chemically cured, Fuji IX GP Extra and resin-modified glass-ionomer cement, Fuji II LC (GC Corporation, Tokyo, Japan). Methods: There were 4 groups for each GIC: one group without the addition of HA particles and three experimental groups with the addition of 2, 5 and 10 $\mathrm{wt} \%$ HA. A sectional Teflon molds ( $8 \mathrm{~mm}$ diameter $\times 2 \mathrm{~mm}$ deep) were used to prepare 10 samples per group $(n=80)$. The specimens were stored in distilled water at $37^{\circ} \mathrm{C}$ for 7 days before testing. The SR was measured using a contact type profilometer and the MH was measured with a Vickers micro-hardness tester at a load of $980 \mathrm{~g}$ for $15 \mathrm{~s}$. Statistical analysis was performed using one-way ANOVA with Tukey post-hoc test. Results and Conclusion: Fuji II modified with $10 \mathrm{wt} \%$ HA showed most favorable results with respect to $\mathrm{MH}$. Comparison of materials with respect to SR showed that there is a difference between them $(p<0.0001$; ANOVA test). Fuji II and Fuji IX modified with HA showed higher surface roughness values which should be considered.
\end{abstract}

Keywords: glass ionomer cements; hydroxyapatite; microhardness; surface roughness

\section{Introduction}

Glass ionomer cements (GICs) are dental materials made of fluoraluminosilicate glass and polyacrylic acid. Since their invention 50 years ago [1], they have been widely used in clinical practice because of their advantages such as chemical bond to dental tissue, biocompatibility, easy handling and fluoride release [2-4].

To overcome their limitations, such as low mechanical properties and brittleness [5], many modifications were performed including optimization of powder liquid ratio and particle size [6]. For instance, Fuji IX GP Extra is a highly viscous material, with a high powder/liquid ratio and smaller particle size, and it exhibited better mechanical properties than conventional GICs [7].

Furthermore, the resin-modified GIC (RMGIC) was developed to overcome early moisture sensitivity and lower mechanical properties associated with conventional GICs [8,9]. In addition to the acid- base reaction in the presence of water, photoinduced polymerization reaction occurs in RMGICs during setting, as they contain resin monomers [10].

Other modifications to improve mechanical properties are performed with the incorporation of various fillers into cement powder, including hydroxyapatite (HA) [11,12]. Recently, the addition of specific percentages of micro- and nano- HA particles to GICs has shown promising results such as 
the increase in adhesive strength to dentin [13] and increased flexural strength [14]. Porous spherical HA particles have been shown to increase mechanical properties and the release of fluoride ions most effectively [14,15]. HA derived from fish bone was reported to be biocompatible, and with no cytotoxic effect on dental pulp cells if incorporated into material [16].

The improvement of the mechanical properties of GIC based materials is of significant clinical importance [5]. The hardness of restorative material is critical for the clinical longevity of restorations, it is an important property in controlling wear resistance and can be used as an indication of likely long-term durability of dental materials [17] and it has been shown that microhardness (MH) is a valid measure of the surface properties of GICs [18,19]. Surface roughness (SR) of GIC materials is often defined as a measure of the wear of materials. An increased roughness can be a predisposing factor for bacterial colonization [20]. When the SR exceeds $0.2 \mu \mathrm{m}$, the caries risk is increased because of bacterial accumulation, plaque maturation, and acidity [21].

To date, there is still lacking data about the impact of porous spherical HA micro-particles derived from the cuttlefish bone on the mechanical properties of GICs, and no data about effects on $\mathrm{SR}$ and MH properties. The objective of this study was to evaluate the effect of incorporation of 2, 5 and $10 \mathrm{wt} \% \mathrm{HA}$, derived from the cuttle-fish bone by the hydrothermal method [22] to VHN and SR properties of GICs. The null hypothesis of this study was that there is no improvement in the VHN and SR properties of glass ionomer cement after the addition of HA.

\section{Materials and Methods}

Highly porous HA was prepared from aragonitic cuttlefish bone (Sepia officinalis) from the Adriatic Sea by using the hydrothermal method. The HA powder in the form of hexagonal column crystal aggregates with a diameter of $<180 \mu \mathrm{m}$ was prepared by grounding and sifting through a 180 $\mu \mathrm{m}$ size sieve. [22]

In this investigation, two GICs were used: Fuji II LC and Fuji IX GP Extra (GC Corporation, Tokyo, Japan). The HA powder 2, 5, and $10 \mathrm{wt} \%$ (three experimental groups) and a glass powder were hand-mixed with a mortar and pestle for $20 \mathrm{~min}$ to obtain a homogenous powder. The prepared powder was then mixed with the polyacrylic acid by spatulation. Four groups were prepared for each GIC material, the first group was without HA particles, while in the powder of three experimental groups was added 2,5 , and $10 \mathrm{wt} \% \mathrm{HA}$, respectively.

A sectional Teflon molds ( $8 \mathrm{~mm}$ diameter $\times 2 \mathrm{~mm}$ deep) were used to prepare 10 samples per group $(n=80)$. After mixing the GIC components by spatulation, the material was poured into a syringe (Centrix, Shelton, CT, USA) and immediately into Teflon molds. To avoid air trapping, polyester strips were placed, and the material was gently compressed on both sides of the mold by glass. Fuji IX specimens were left for one hour to allow the material to set. Both sides of each Fuji II sample were light-cured for $20 \mathrm{~s}$ to ensure a perfect setting by using a LED lamp (Ivoclar Vivadent AG, Schaan, Lichtenstein, Germany), with intensity $600 \mathrm{~mW} / \mathrm{cm}^{2}$. The specimens were stored in distilled water at $37{ }^{\circ} \mathrm{C}$ for 7 days and than tested. There were conducted SR measurements and then $\mathrm{MH}$ measurements on the same specimens.

SR was measured using a contact type profilometer device (Perthometer M2, Mahr GmbH, Gottingen, Germany). Multidirectional readings were made for each specimen in five different areas. After five sequential measurements were performed at different locations for each specimen, the arithmetic mean of SR was obtained. Specimens were fixed with a special jig to ensure their position is the same for all measurements.

The VHN measurements were performed using a digital microhardness tester (HMV-2, Shimadzu Corp., Kyoto, Japan). A $980 \mathrm{~N}$ force was applied to the specimens with a diamond indenter for $15 \mathrm{~s}$. The testing machine was calibrated before each measurement. Microhardness indentations were made after the specimen surfaces were divided into four quadrants. Two measurements were taken in each quadrant, totaling eight measurements. The mean of the 8 measurements represented specimen mean. These points were not at the margins or areas with visible irregularity.

One specimen from each group was sputter-coated with gold and observed under Scanning Electron Microscope (SEM) (JSM-6400 SEM, JEOL, Tokyo, Japan), $\times 100$ magnifications. 
Regarding a statistical analysis of the data, a descriptive analysis was performed. Normality distribution was checked with the Shapiro-Wilk test while equality of variances was tested with Levene's test. Due to heterogeneity of variances (Levene's test; $p=0.0265$ for surface roughness and $p<0.0001$ for microhardness) Welch's one-way ANOVA and a post-hoc Tukey's test were performed. The analysis was conducted using a SAS statistical package on a Windows platform. The level of significance was set at $p=0.05$.

\section{Results}

Descriptive statistics for SR and MH properties in the eight groups are shown in Tables 1 and 2, respectively.

Table 1. Descriptive statistics for Surface Roughness (SR).

\begin{tabular}{|c|c|c|c|c|c|}
\hline Material & $\mathbf{N}$ & Mean (Ra) & $\begin{array}{l}\text { Standard } \\
\text { Deviation }\end{array}$ & $\begin{array}{c}95 \% \text { CI } \\
\text { Lower Bound }\end{array}$ & $\begin{array}{c}95 \% \text { CI } \\
\text { Upper Bound }\end{array}$ \\
\hline Fuji IIO & 10 & 0.062 & $(0.011)$ & 0.054 & 0.070 \\
\hline Fuji II2 & 10 & 0.069 & $(0.013)$ & 0.059 & 0.078 \\
\hline Fuji II5 & 10 & 0.080 & $(0.010)$ & 0.073 & 0.087 \\
\hline Fuji II10 & 10 & 0.089 & $(0.011)$ & 0.081 & 0.097 \\
\hline Fuji IX0 & 10 & 0.176 & $(0.032)$ & 0.153 & 0.199 \\
\hline Fuji IX2 & 10 & 0.221 & $(0.068)$ & 0.172 & 0.269 \\
\hline Fuji IX5 & 10 & 0.192 & $(0.027)$ & 0.173 & 0.212 \\
\hline Fuji IX10 & 10 & 0.254 & $(0.040)$ & 0.226 & 0.282 \\
\hline
\end{tabular}

Table 2. Descriptive statistics for Microhardness (MH).

\begin{tabular}{cccccc}
\hline Material & N & Mean & $\begin{array}{c}\text { Standard } \\
\text { Deviation }\end{array}$ & $\begin{array}{c}\text { 95\% CI } \\
\text { Lower Bound Upper Bound }\end{array}$ & $\begin{array}{c}\text { 95\% CI } \\
\text { Upper }\end{array}$ \\
\hline Fuji II0 & 10 & 55.2 & $(5.3)$ & 51.4 & 58.9 \\
Fuji II2 & 10 & 47.5 & $(4.1)$ & 44.6 & 50.5 \\
Fuji II5 & 10 & 53.0 & $(5.7)$ & 48.9 & 57.0 \\
Fuji II10 & 10 & 61.5 & $(4.8)$ & 58.1 & 64.9 \\
Fuji IX0 & 10 & 50.6 & $(4.3)$ & 47.5 & 53.7 \\
Fuji IX2 & 10 & 48.9 & $(4.2)$ & 45.9 & 51.9 \\
Fuji IX5 & 10 & 47.2 & $(9.8)$ & 40.2 & 54.2 \\
Fuji IX10 & 10 & 40.7 & $(7.0)$ & 35.7 & 45.6 \\
\hline
\end{tabular}

The results of the material comparison are shown in Table 3.

Table 3. Results of the ANOVA test for Fuji II and Fuji IX.

\begin{tabular}{ccccc}
\hline Material & $\begin{array}{c}\text { Surface Roughness } \\
(\text { Ra) }\end{array}$ & \multicolumn{2}{c}{ Microhardness } \\
\hline Fuji II0 & 0.062 & $\mathrm{a}$ & 55.2 & $\mathrm{ab}$ \\
Fuji II2 & 0.069 & $\mathrm{a}$ & 47.5 & $\mathrm{bc}$ \\
Fuji II5 & 0.080 & $\mathrm{a}$ & 53.0 & $\mathrm{~b}$ \\
Fuji II10 & 0.089 & $\mathrm{a}$ & 61.5 & $\mathrm{a}$ \\
Fuji IX0 & 0.176 & $\mathrm{~b}$ & 50.6 & $\mathrm{~b}$ \\
Fuji IX2 & 0.221 & $\mathrm{bc}$ & 48.9 & $\mathrm{~b}$ \\
Fuji IX5 & 0.192 & $\mathrm{~b}$ & 47.2 & $\mathrm{bc}$ \\
Fuji IX10 & 0.254 & $\mathrm{c}$ & 40.7 & $\mathrm{c}$ \\
\hline$p^{*}$ & $<0.0001$ & & $<0.0001$ & \\
\hline
\end{tabular}

* $p$-value for ANOVA test; $\mathrm{a}, \mathrm{b}, \mathrm{c}-$ materials with the same letter are not significantly different (Tukey test). 
Comparison of materials with respect to SR shows that there is a difference between them $(p<$ 0.0001; ANOVA test). The results of the multiple comparison (Tukey test) with respect to SR show that values for Fuji IX are higher on average in comparison to the values for Fuji II irrespective of HA concentration. There is no evidence that SR depends on HA concentration for Fuji II although values of SR increases with the increase of HA concentration (differences in SR between Fuji II control group, Fuji II 2 wt\% HA, Fuji II 5 wt\% HA and Fuji II 10wt\% HA were not found significant). For Fuji IX, SR also generally increases with the increase of HA concentration. Raughness of Fuji IX $10 \mathrm{wt} \%$ HA was statistically higher than the SR of Fuji IX without HA and Fuji IX 5 wt $\%$ HA.

There is difference with respect to MH between the groups, too $(p<0.0001$; ANOVA test). A trend of higher microhardness for Fuji II than for Fuji IX was recorded. Exception is MH for 2 wt $\%$ HA where mean for Fuji IX sample is higher than mean for Fuji II sample. The addition of HA to Fuji II is not conclusive. Lowest microhardness is observed for $2 \mathrm{wt} \% \mathrm{HA}$, but Tukey test shows that $\mathrm{MH}$ of Fuji II with $10 \mathrm{wt} \%$ HA is significantly higher. In Fuji IX groups, it was observed that increase of HA concentration decreases microhardness. However, only the difference between $10 \mathrm{wt} \% \mathrm{HA}$ concentration and $2 \mathrm{wt} \% \mathrm{HA}$ concentration and the difference between $10 \mathrm{wt} \%$ HA concentration and group without HA particles added are significant. There is no evidence that $\mathrm{MH}$ for the group without HA particles and groups with $2 \mathrm{wt} \% \mathrm{HA}$ and $5 \mathrm{wt} \%$ HA differ.

The observed SEM images of representative of one specimen from each group are shown in Figure 1.
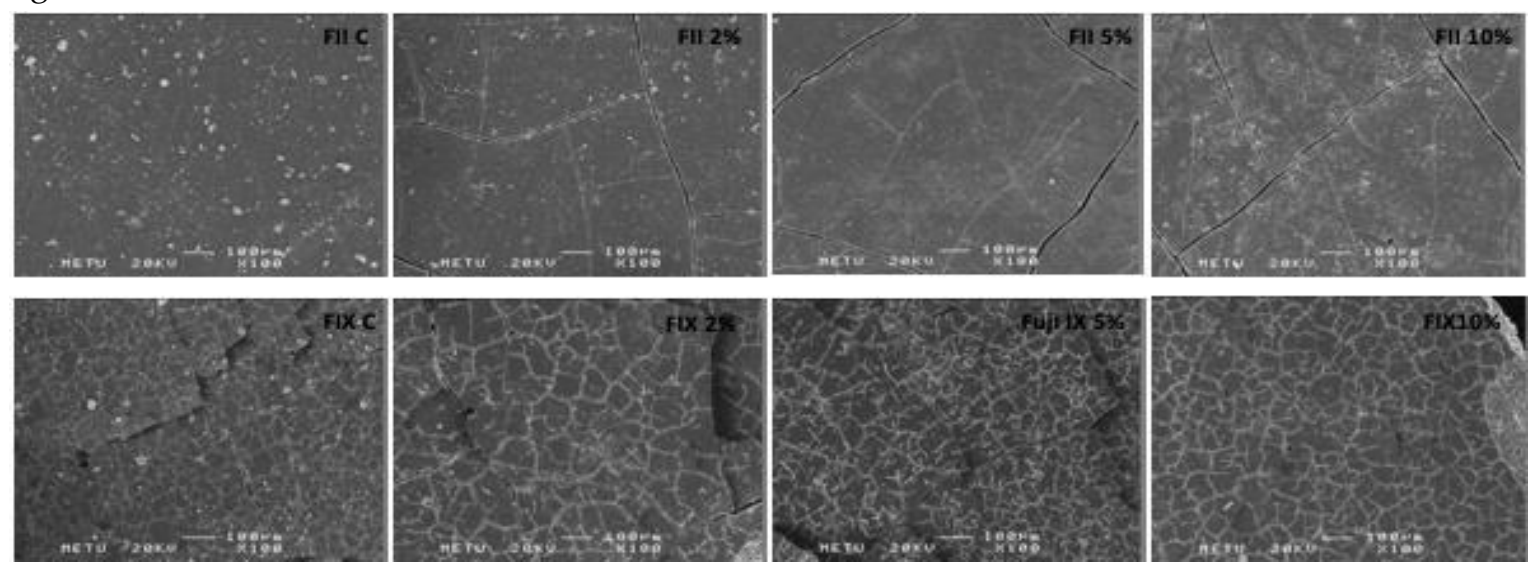

Figure 1. Representative SEM photomicrographs ( $\times 100$ magnification) of a Fuji II (first row): Fuji II (without HA particles), Fuji II 2 wt $\%$ HA, Fuji II 5 wt $\%$ HA, Fuji II 10 wt $\%$ HA respectively; and Fuji IX (2nd row): Fuji IX (without HA particles), Fuji IX 2 wt \% HA, Fuji IX 5 wt $\%$ HA, Fuji IX 10 wt\% HA respectively.

The SEM images display small glass particles dispersed in the matrix. SEM images of Fuji II, either the group without HA added or experimental groups displayed predominantly smooth, and featureless surfaces (Figure 1a-d) but cracks or voids were evident on the surfaces of HA added specimens (b-d) in contrast to the group without HA (a). The surfaces of Fuji IX (e-h) appeared relatively rough demonstrating macro defects on the surfaces.

\section{Discussion}

The results of this study showed that the addition of marine derived HA partices to commercially available GIC materials influenced SR and MH. SR of Fuji II did not significantly increase after the addition of HA particles, while in Fuji IX it was significantly higher in Fuji IX 10wt\% HA group than in the group withoud HA particles added. The addition of HA articles reduced MH of Fuji IX, but not significantly, while MH in Fuji II 10\%wt HA was higher than in the group without the addition of HA particles. Nul hypothesis was thus rejected.

For the longevity and success of the restoration, two important properties are hardness and surface characteristics of the restorative material [23]. Average roughness (Ra) is the most commonly used parameter to describe SR measured with a profilometer and the scanning electron microscope 
(SEM) is requested for a more detailed analysis, as profilometers provide only two-dimensional information.

Among many attempts to improve characteristics of GICs by addition of different fillers, porous spherical HA particles have shown promising results [14,15]. HA particles are found in two main forms, nano- and micro- size [24]. Nano-HA-filled materials were found rougher comparing with the materials comprising micro-HA, which displayed low SR values [25]. Due to that, micrometric-HA was chosen for this study. Also, micro-particles of HA are easily mixed with resin and nano-HA considerably prolongs the setting time of GICs [26].

It was concluded earlier that the lowest SR of GICs materials was found in the surface in contact with the Mylar strip. However, in clinical condition is difficult to achieve the right morphology of filling only by using the Mylar strip [27]. There is usually a problem during the finishing and polishing of GICs due to the heterogeneity of the composition and the difference in hardness between the inorganic fillers and the matrix that leads to non-uniform abrasion [28]. In our study, SR values for Fuji II were significantly lower in comparison to the values for Fuji IX with no dependence on HA concentration, what 6 sin accordance with the study of Hoda S. Ismail et al. [29], which may be due to its smaller filler size $(0.02-0.04 \mu \mathrm{m})$. Additional SEM analysis showed predominantly smooth, and featureless surfaces in Fuji II specimens, while the surfaces of Fuji IX appeared relatively rough demonstrating macro defects on the surfaces. The incorporation of resin has added resin polymerization setting reaction, making the material mature faster. The results have shown that Ra values of Fuji II have increased with the increase of HA concentration, but not statistically significant. Only Fuji IX $2 \mathrm{wt} \%$ HA and $10 \mathrm{wt} \%$ HA showed Ra value $>0.2$, which could be clinically significant [21]. With SEM analysis, cracks or voids were evident on the surfaces of HA added specimens. It could be because the HA particles formed by hydrothermal conversion have a cauliflower-like morphology, thus increasing the surface roughness and specific surface energy [22].

Yli Up et al. Studied the VHN of the GIC and RMGI with 10\% or 30\% HA [30]. They reported that the hardness of glass-ionomers decreased as the amount of hydroxyapatite increased, which 6 sin accordance with results of our study. Contrary to that, they showed that the hardness values of conventional GICs were higher than light-cured glassionomers. The explanation for difference in results could be explained that the MH of HA-added Fuji II increased during water storage [19], also the larger particle sizes and fewer voids and cracks of RMGI resulted in higher microhardness values. Probably, conventional and RMGICs placed in the oral environment would not be affected to the same extent as in in vitro tests. Among all the 8 groups, RMGI (Fuji II) with $10 \mathrm{wt} \% \mathrm{HA}$ had the highest VHN value (61.5). When compared to an earlier study where the group with $10 \mathrm{wt} \% \mathrm{HA}$ had the highest flexural strength value [12], it could be concluded that this exact concentration of HA particles could improve two important physical properties of Fuji II. This result is in agreement with Lee's survey, which was shown that the physical properties of RMGI improved with the incorporation of 10\% nano- and micro- HA [24]. Few investigations are concluding that $5 \mathrm{wt} \% \mathrm{HA}$ resulted in improved mechanical properties, such as compressive strength and $\mathrm{MH}[31,32]$. This difference could be explained with possible ununiformed glass- HA powder (manual mixing) or inadequate liquid amount, as the volume of HA can change the reaction.

\section{Conclusions}

This study showed that the addition of micro-HA derived from cuttlefish bone to the powders of Fuji IX and Fuji II did not improve the SR, indeed, the SR increased compared to groups without HA added. Regarding $\mathrm{MH}$, the addition of HA decreased $\mathrm{MH}$ in all groups except the Fuji II $10 \mathrm{wt} \% \mathrm{HA}$ group, for which the highest $\mathrm{MH}$ value was obtained. This study had an in vitro design and the limitations inherent to in vitro studies; thus, the generalizability of the results to clinical setting must be done with caution. Future studies are required to assess the effect of the addition of $10 \mathrm{wt} \% \mathrm{HA}$ on physical and chemical properties of RMGIC, Fuji II LC. 
Author Contributions: Conceptualization, I.M.; methodology, M.B.-P.; validation, M.B.-P. and A.I.; formal analysis, S.G.; investigation, S.G. and U.K.V.; resources, I.M.; writing-original draft preparation, M.B.-P. and U.K.V. writing - review and editing S.G. and S.J.K.; visualization, A.I. and S.J.K.; supervision, I.M.; funding acquisition, I.M. All authors have read and agreed to the published version of the manuscript.

Funding: This study was founded by the Croatian Science Foundation, which is dedicated to the "Investigation and development of new micro and nanostructure bioactive materials in dental medicine" (BIODENTMED No. IP-2018-01-1719).

Acknowledgments: Special thanks to Hrvoje Ivankovic and Ana Marija Rogina from the Faculty of Chemical Engineering and Technology, University of Zagreb for providing hydroxyapatite derived from cuttlefish bone.

Conflicts of Interest: The authors declare no conflict of interest. The funders had no role in the design of the study; in the collection, analyses, or interpretation of data; in the writing of the manuscript, or in the decision to publish the results.

\section{References}

1. Wilson, A.D.; Kent, B.E. Surgical Cement. British Patent No. 1316129, 9 May 1973.

2. Da Silva, R.C.; Zuanon, A.C.C. Surface Roughness of Glass Ionomer Cements Indicated for Atraumatic Restorative Treatment (ART). Braz. Dent. J. 2006, 17, 106-109.

3. Sidhu, S.K.; Nicholson, J.W. A review of glass-ionomer cements for clinical dentistry. J. Funct. Biomater. 2016, 7, 16.

4. Hotz, P.; McLean, J.W.; Sced, I.; Wilson, A.D. The bonding of glass ionomer cements to metal and tooth substrates. Br. Dent. J. 1977, 142, 41-47.

5. Peutzfeldt, A.; García-Godoy, F.; Asmussen, E. Surface hardness and wear of glass ionomers and compomers. Am. J. Dent. 1997, 10, 15-17.

6. Davidson, C.L. Advances in glass-ionomer cements. J. Appl. Oral. Sci. 2006, 14, 3-9.

7. Šalinović, I.; Stunja, M.; Schauperl, Z.; Verzak, Ž.; Ivanišević Malčić, A.; Brzović Rajić, V. Mechanical Properties of High Viscosity Glass Ionomer and Glass Hybrid Restorative Materials. Acta Stomatol. Croat. 2019, 53, 125-131.

8. Mitra, S.B. Adhesion to dentin and physical properties of a light-cured glass-ionomer liner/base. J. Dent. Res. 1991, 70, 72-74.

9. Sidhu, S.K.; Watson, T.F. Resin-modified glass ionomer materials. A status report for the American Journal of Dentistry. Am. J. Dent. 1995, 8, 59-67.

10. Popoff, J.M.D.S.; Rodrigues, J.; Aras, W.M.D.F.; Cassoni, A. Influence of Photoactivation Source on Restorative Materials and Enamel Demineralization. Photomed. Laser Surg. 2014, 32, 274-280.

11. Alatawi, R.A.S.; Elsayed, N.H.; Mohamed, W.S. Influence of hydroxyapatite nanoparticles on the properties of glass ionomer cement. J. Mater. Res. Technol. 2019, 8, 344-349.

12. Gjorgievska, E.; Nicholson, J.W.; Gabrić, D.; Guclu, Z.A.; Miletić, I.; Coleman, N.J. Assessment of the Impact of the Addition of Nanoparticles on the Properties of Glass-Ionomer Cements. Materials 2020, 13, 276.

13. Moshaverinia, A.; Ansari, S.; Movasaghi, Z.; Billington, R.W.; Darr, J.A.; Rehman, I. Modification of conventional glass-ionomer cements with $\mathrm{N}$-vinylpyrrolidone containing polyacids, nano-hydroxy and fluoroapatite to improve mechanical properties. Dent. Mater. 2008, 24, 1381-1390.

14. Bilić-Prcić, M.; Brzović Rajić, V.; Ivanišević, A.; Pilipović, A.; Gurgan, S.; Miletić, I. Mechanical Properties of Glass Ionomer Cements after Incorporation of Marine Derived Hydroxyapatite. Materials 2020, 1, 3542.

15. Arita, K.; Yamamoto, A.; Shinonaga, Y.; Harada, K.; Abe, Y.; Nakagawa, K.; Sugiyama, S. Hydroxyapatite particle characteristics influence the enhancement of the mechanical and chemical properties of conventional restorative glass ionomer cement. Dent. Mater. J. 2011, 30, 672-683.

16. Yamamura, H.; Da Silva, V.H.P.; Ruiz, P.L.M.; Ussui, V.; Lazar, D.R.R.; Renno, A.C.M.; Ribeiro, D.A. Physico-chemical characterization and biocompatibility of hydroxyapatite derived from fish waste. J. Mech. Behav. Biomed. Mater. 2018, 80, 137-142.

17. Nicholson, J.W. Chemistry of glass-ionomer cements: A review. Biomaterials 1998, 19, 485-494.

18. Shintome, L.K.; Nagayassu, M.P.; Di Nicoló, R.; Myaki, S.I. Microhardness of glass-ionomer cements indicated for the ART technique according to surface protection treatment and storage time. Braz. Oral. Res. 2009, 23, 439-445.

19. Ellakuria, J.; Triana, R.; Minguez, N.; Soler, I.; Ibaseta, G.; Maza, J. Effect of one-year water storage on the 
surface microhardness of resin-modified versus conventional glass-ionomer cements. Dent. Mater. 2003, 19, 286-290.

20. Bollen, C.M.L.; Lambrechts, P.; Quirynen, M. Comparison of surface roughness of oral hard materials to the threshold surface roughness for bacterial plaque retention: A review of the literature. Dent. Mater. 1997, 13, 258-269.

21. Yap, A.U.; Lye, K.W.; Sau, C.W. Surface characteristic of tooth coloured restoration polished utilizing. different polishing systems. Oper. Dent. 1997, 22, 260-265.

22. Rogina, A.; Antunović, M.; Milovac, D. Biomimetic design of bone substitutes based on cuttlefish bonederived hydroxyapatite and biodegradable polymers. Biomed. Mater. Res. B Appl. Biomater. 2019, 107, 197-204.

23. Prabhakar, A.R.; Paul, M.J.; Basappa, N. Comparative Evaluation of the Remineralizing Effects and Surface Micro hardness of GlassIonomer Cements Containing Bioactive Glass (S53P4): An in vitro Study. Int. J. Clin. Pediatr. Dent. 2010, 3, 69-77.

24. Lee, J.J.; Lee, Y.K.; Choi, B.J.; Lee, J.H.; Choi, H.J.; Son, H.K. Physical properties of resin-reinforced. glass ionomer cement modified with micro and nano-hydroxyapatite. J. Nanosci. Nanotechnol. 2010, 10, 52705276.

25. Domingo, C.; Arcis, R.W.; Lopez-Macipe, A.; Osorio, R.; Rodriguez-Clemente, R.; Murtra, J.; Toledano, M. Dental composites reinforced with hydroxyapatite: Mechanical behavior and absorption/elution characteristics. J. Biomed. Mater. Res. 2001, 56, 297-305.

26. Venhoven, B.A.M.; de Gee, A.J.; Werner, A.; Davidson, C.L. Influence of filler parameters on the mechanical coherence of dental restorative composites. Biomaterials 1996, 17, 735-740.

27. Pedrini, D.; Candido, M.S.M.; Rodrigues, A.L. Analysis of surface roughness of glass-ionomer cements and compomer. J. Oral. Rehabil. 2003, 30, 714-719.

28. Madhyastha, P.S.; Hegde, S.; Srikant, N.; Kotian, R.; Iyer, S.S. Effect of finishing/polishing techniques and time on surface roughness of esthetic restorative materials. Dent. Res. J. 2017, 14, 326-330.

29. Hoda, S.I.; Ashraf, I.A.; Mohammed, A.A.E.-E.; Salah, H. Effect of different polishing techniques on surface roughness and bacterial adhesion of three glass ionomer-based restorative materials: In vitro study. J. Clin. Exp. Dent. 2020, 12, e620-e625.

30. Yli-Urpo, H.; Lassila, L.V.; Närhi, T.; Vallittu, P.K. Compressive strength and surface characterization of glass ionomer cements modified by particles of bioactive glass. Dent. Mater. 2005, 21, 201-209.

31. Sharafeddin, F.; Shoale, S.; Kowkabi, M. Effects of Different Percentages of Microhydroxyapatite on Microhardness of Resin-modified Glass-ionomer and Zirconomer. J. Clin. Exp. Dent. 2017, 9, e805.11.

32. Khaghani, M.; Doostmohammadi, A.; Monshi, A.; Golnia, Z. Effect of incorporating nano- particles of hydroxyapatite on bioactivity and compressive strength of dental glass-ionomer cements. J. Isfahan Dent. Sch. 2013, 8, 593-605.

Publisher's Note: MDPI stays neutral with regard to jurisdictional claims in published maps and institutional affiliations.

(C) 2020 by the authors. Submitted for possible open access publication under the terms and conditions of the Creative Commons Attribution (CC BY) license (http://creativecommons.org/licenses/by/4.0/). 